\title{
Getting the Strain Under Control: Trans-Varestraint Tests for Hot Cracking Susceptibility
}

\author{
DIMITRIOS STATHARAS, HELEN ATKINSON, ROB THORNTON, \\ JOHN MARSDEN, HONGBIAO DONG, and SHUWEN WEN
}

\begin{abstract}
A new method for conducting Trans-Varestraint tests for assessing hot cracking susceptibility is proposed. Experiments were carried out, to validate the new method, with an industrial scale rig using tungsten inert gas welding. The hot cracking susceptibility of API-5L X65 and EN3B steel was compared. The results indicated that, by using the new method, the strain applied to the welding bead and consequently to the solidification front was controlled in a repeatable and reliable way. The results also indicated that EN3B has a maximum crack length (a parameter in the test) higher than X65 and it is reached at lower augmented strain thus demonstrating it is more susceptible to hot cracking, while also indicating that there is a capability of predicting the initiation position of hot cracks during welding. By using the method proposed, the capability of setting standardized test procedures for Trans-Varestraint tests is improved. It is recommended that future tests for assessing hot cracking susceptibility should employ the proposed method in order for the results to be comparable and to also study the effect of strain rate in hot cracking of materials.
\end{abstract}

https://doi.org/10.1007/s11661-019-05140-0

(C) The Author(s) 2019

\section{INTRODUCTION}

VARIOUS methods for assessing hot cracking susceptibility of materials have been explored since Prokhorov $^{[1,2]}$ and Matsuda ${ }^{[3-7]}$ defined the term brittle temperature range (BTR) and introduced the working principle of Varestraint and Transverse Varestraint (Trans-Varestraint) tests. Other methods for assessing hot cracking susceptibility include the Cast-pin tear test, ${ }^{[8,9]}$ ductility-dip cracking, ${ }^{[10]}$ and Gleeble tests. ${ }^{[11,12]}$ All of these methods have improved the assessment and quantification of hot cracking but still lack the repeatability and reliability required to give a definitive assessment of hot cracking susceptibility. ${ }^{[13]}$ Furthermore, as the hot cracking phenomenon is more extensively researched, new models for crack generation and

DIMITRIOS STATHARAS, ROB THORNTON and HONGBIAO DONG are with the Department of Engineering, EPSRC Centre for Doctoral Training in Innovative Metal Processing (IMPaCT), University of Leicester, University Road, Leicester, LE1 7RH, UK. Contact e-mail: rob.thornton@leicester.ac.uk HELEN ATKINSON is with the School of Aerospace, Transport and Manufacturing, Cranfield University, Cranfield, MK43 0AL, UK. JOHN MARSDEN is with Tata Steel, Research and Development, Swinden Technology Centre, Moorgate, Rotherham, S60 3AR, UK. SHUWEN WEN is with the Dongguan Centre of Excellence for Advanced Materials, Dongguan, Guangdong, China.

Manuscript submitted August 3, 2018.

Article published online February 12, 2019 development are emerging. Recent developments that have been presented in 2017 and 2018 by Aucott et al. include the three-stage mechanistic model for solidification cracking during welding of stee ${ }^{[14]}$ and the initiation and growth kinetics of solidification cracks during welding. ${ }^{[15]}$ Solidification in general is affected by the temperature gradients that are forming during the process and the direction of heat flow. ${ }^{[16]}$ During welding the heat flow is not the same as it would be during the free solidification of materials because of the movement of the heat source and the existence of solid material at the edge of the weld pool. This acts as a nucleation area for the solidification of the material and allows for the material to solidify in a specific direction forming columnar grains that are oriented towards the heat source. ${ }^{[17]}$ Adding to that the grains that grow during this process are competing for their growth in a similar way that grains compete during the directional solidification. ${ }^{[18,19]}$ Because of the heat exchange and the difference in temperature during the solidification, material properties like density and heat capacity are changing. These changes in combination with the changes on the composition of the molten liquid in the solidification front has shown to create strains and stresses in the solidifying materials. ${ }^{[19,20]}$ It is during these processes, both during welding and casting, that defects like hot cracking manifest. The combination of the improved understanding of the hot cracking phenomenon and the need for further development of methods for assessing hot cracking susceptibility led to 
the main subject of this study. Some guidelines for these tests are presented in current technical reports (ISO-TR 17641-3:2005) which focus on destructive tests on welds in general. ${ }^{[21]}$ Nevertheless, there are no dedicated standards focusing on these tests in detail. The present study proposes a new method for conducting the Trans-Varestraint test with the objectives of improving its reliability and facilitating its standardization to assess the hot cracking susceptibility of materials.

\section{THE TRANS-VARESTRAINT TEST}

The Trans-Varestraint and Varestraint tests were established in the early 1960 s and 1970 s. $^{[3,22-24]}$ These tests involve placing a specimen on a rig with a similar arrangement to a three-point bend test, initiating a welding process and towards the end of the welding process bending the specimen to achieve a pre-determined strain, using a former of a prescribed radius. The direction of the weld is either in the plane of bending (Varestraint) or perpendicular to the plane of bending (Trans-Varestraint), as illustrated in Figure 1.

The radius of the former $(R)$ is determined from the specimen thickness $(t)$ and the target strain to be applied $(\varepsilon)$, according to Eq. [1]. This strain is defined as the 'augmented strain.' During solidification, weld strains are generated at the solidification front due to shrinkage. These strains can be augmented by imposing strains by bending. ${ }^{[25]}$

$$
\varepsilon=\frac{t}{2 R} \times 100
$$

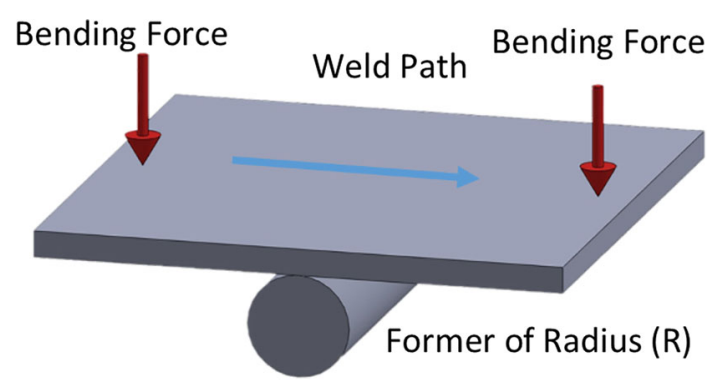

(a)

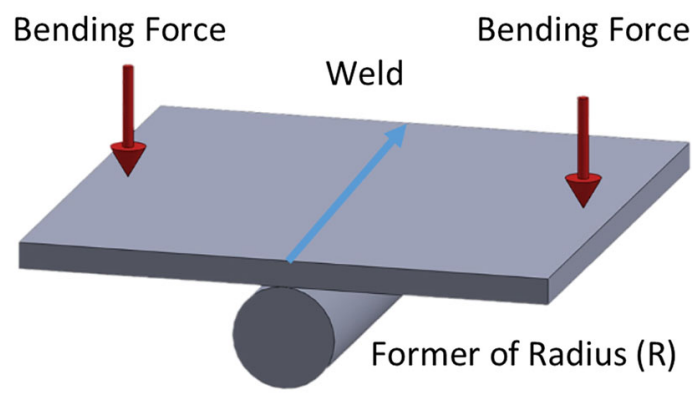

(b)
As the bend is applied during the welding process, additional strain is applied on the welding bead and, consequently, on the solidification front. This, depending on the materials resistance to hot cracks, can lead in crack initiation. After the end of the tests, cracks that are formed on the surface of the specimen are measured, usually with the use of a stereoscope, and plotted against the augmented strain. Because the orientation, position, and number of cracks differs between the two tests (Varestraint and Trans-Varestraint), three different crack measurements have been utilized for these tests: Maximum Crack Length (MCL), Total Crack Length (TCL), and Maximum Crack Distance (MCD). MCL is the length of the biggest crack. TCL is the sum of the lengths of all the cracks present after the experiment. MCD is the maximum distance parallel to the welding path that a crack has traveled. In the case of the Varestraint test, because the cracks are not generated along the centerline of the weld, the MCD and MCL may refer to different cracks. For the Trans-Varestraint test, the MCL and MCD can refer to the same crack as the biggest cracks are generated along the centerline of the weld (Figure 2).

The exact time that the bend should be imposed has not previously been fixed and no parameters were set for this. ${ }^{[26]}$ This means that experiments can potentially be carried out by bending at the start of the welding process where the welding bead has not been fully formed and stabilized thermodynamically, resulting to higher tensile stresses applied on the material. ${ }^{[27]}$ Given that the welding process is not in a steady state at the moment of initiation of the weld, delaying the time of the bend would allow for the welding process to reach a steady state. Furthermore, the stroke of the bend and the bending rate are also not set. Using these tests has allowed though for some specific parameters and properties to be quantified and connected to the hot cracking susceptibility of the materials.

In the early 1960s, a brittle temperature range (BTR) was identified, during which materials presented low ductility. ${ }^{[1,2]}$ This was determined by measuring the temperature of the weld pool and by correlating crack lengths with the temperature gradient to identify the BTR of the material (Figure 3).

In order to incorporate the energy input on the weld, the solidification cracking temperature range (SCTR) was introduced. This was identified by conducting the test as previously described, resulting in a plot of maximum crack distance vs augmented strain (Figure 4). The augmented strain above which the crack length ceased to increase was then identified and defined as the 'saturated strain' condition.

This saturated strain crack length was used in combination with the welding speed and cooling rate to calculate the SCTR according to Eq. [2] and Figure 5. ${ }^{[13]}$

$$
\mathrm{SCTR}=\text { Cooling rate } \times \frac{\text { MaximumCrackDistance }(\mathrm{MCD})}{\text { Welding Velocity }(V)} .
$$

Fig. 1-(a) Varestraint test. (b) Trans-Varestraint test. 

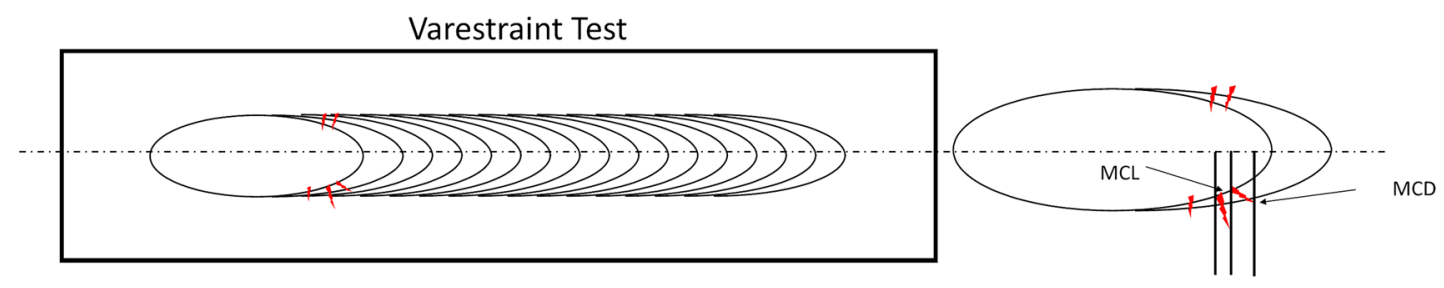

Trans-Varestraint Test

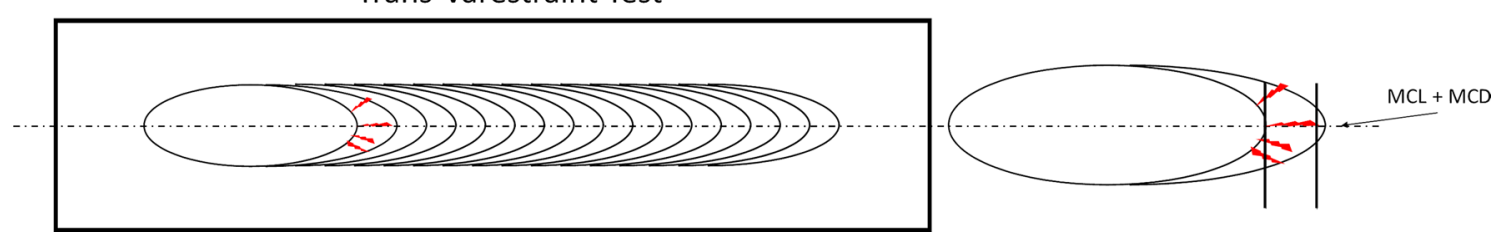

Fig. 2-Definition of maximum crack length and maximum crack distance and their differences between the Varestraint and Trans-Varestraint tests.

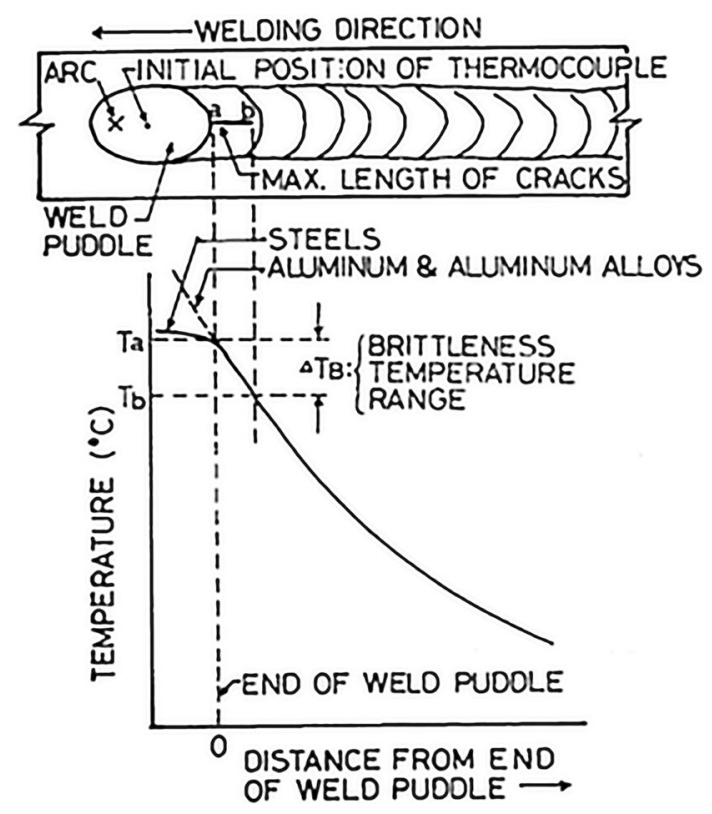

Fig. 3-Definition of the Brittle Temperature Range using the results of Trans-Varestraint test (reprinted from Ref. [3], with permission).

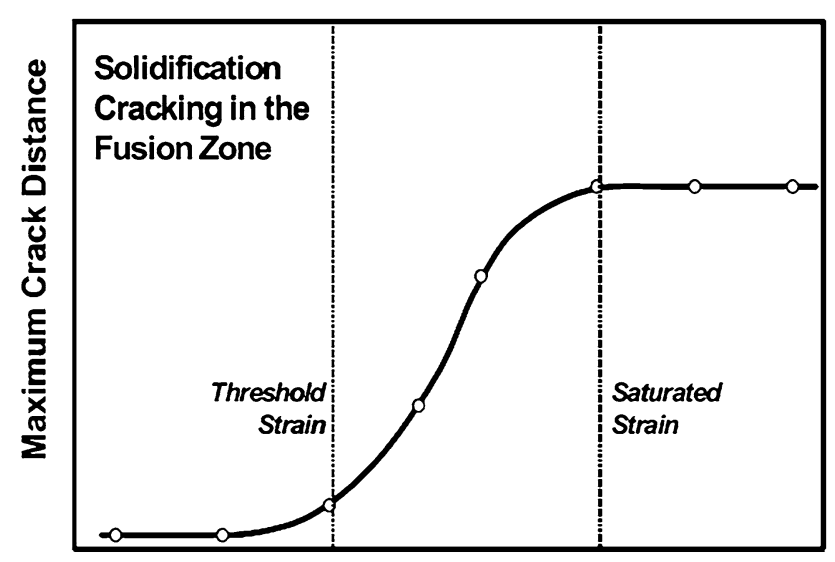

Augmented Strain

Fig. 4-Augmented strain vs Crack length (reprinted from Ref. [13]).

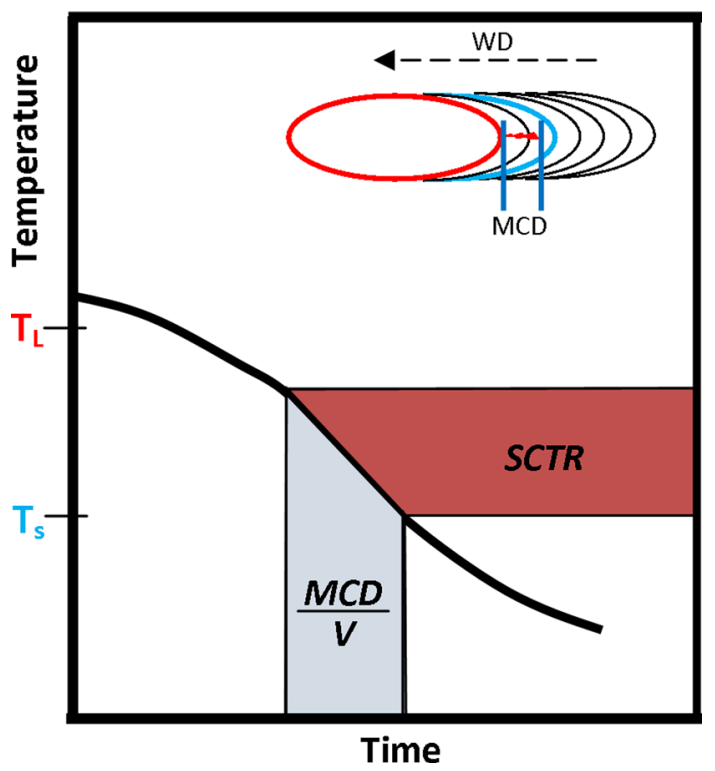

Fig. 5-Solidification cracking temperature range calculation on a temperature $v$ s time graph (adapted from Ref. [28]).

Despite these developments, a global agreement on how hot susceptibility should be tested has not yet been reached. Some of the main reasons preventing a standardized approach are as follows:

- Lack of an optimal apparatus setup to conduct the experiments with

- Lack of a specific way to apply the augmented strain during the experiment

- Lack of an optimal strain rate that should be used for the experiment

- Lack of specimen specifications

- Lack of specification of welding time.

Additionally, investigators have recently stated that controlling the strain and strain rate during these experiments is a challenging issue that has not yet been addressed. ${ }^{[29]}$ These are key parameters that need to be specified since they are critical to the mechanism of hot cracking, which is a strain-driven phenomenon. This 
paper if mainly focused on addressing the way the augmented strain is applied during the experiments and defining guidelines on the optimal apparatus setup in order to conduct the experiments with.

\section{METHOD}

\section{A. The Basis of a Standardized Testing Methodology}

In order to create a standardized testing methodology, the following aspects must be addressed:

- Every test shall be carried out using a standard setup that ensures repeatability and comparison of results. The primary parameter that affects solidification cracking in these tests is the strain applied on the weld, which is determined by the radius of the formers used according to Eq. [1]. By defining standard discrete former radii, a selection table (e.g., Figure 6) could be used to ensure the desired strain, according to the thickness of the specimen. ${ }^{[30]}$

- The actual bending stroke resulting in the required strain should be defined. Published research has not yet defined this relationship. Tests have instead been carried out with a variety of formers, welding techniques, and strain rates. ${ }^{\text {3,25,30-32] }}$

- An appropriate measurable parameter for crack length, from which hot cracking susceptibility can be reliably determined, should be identified and defined.

Without addressing these aspects, there are three possible test outcomes. The specimens will either be under bent, fully bent, or over bent (Figure 7). If the specimen is under bent, the strain applied on the centerline will be less than desired. If the specimen is over bent, the strain will be more than desired. In order to ensure that the strain applied matches the target strain, the bend must form a tangent to the surface of the former.

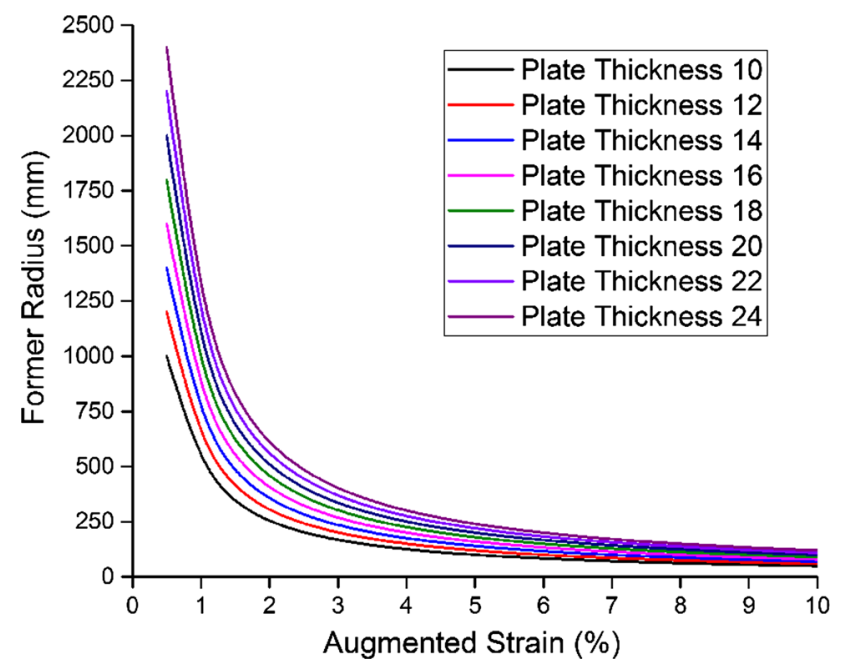

Fig. 6-Selection of former radius $(R)$ using the specimen thickness and the desired augmented strain.
To determine the required stroke to be used, a geometrical approach needs to be utilized (Figure 8). The test has a similar geometric arrangement to a three-point bend test with a former of a specific radius that ensures that the centerline of the specimen is bent to a specific radius in order for the target strain to be applied.

To improve reliability and repeatability, the length of bending stroke (labeled $\mathrm{S}$ in Figure 8 ) must be precisely controlled. The bending stroke must be sufficient to ensure that the specimen will utilize the full surface of the former and will always be in contact with it.

The bending stroke may be derived from one half of the bending setup, setting the maximum bend as the bend where the plate will follow a tangent line from the edge of the former. Figure 9 illustrates the relevant geometry, where

$A A^{\prime}$ is the half-bending span between former centerline and actuator $(L)$,

$C C^{\prime}$ is half-width of the former $(W)$,

$D C^{\prime}$ and $D A$ are the radii of the former $(R)$, and

$A^{\prime} B^{\prime}$ is the length of the stroke $(S)$.

From Figure 9, it can be seen that triangles $A O B$ and $A^{\prime} O B^{\prime}$ are similar. Adding to that the angle formed between the sides $A O$ and $B O$ of the triangle $A O B$ (referred to as $\theta$ from now on) is the same as the angle that is formed by the sides $D C^{\prime}$ and $D C$ from the triangle $D C C^{\prime}$. This means that all the trigonometric numbers that are the result of these angles in these triangles will be the same. For this reason, we have the following.

For the triangle $D C C^{\prime}$,

$$
\begin{gathered}
\sin \theta=\frac{W}{R} \\
\cos \theta=\frac{\sqrt{R^{2}-W^{2}}}{R} \\
\tan \theta=\frac{W}{\sqrt{R^{2}-W^{2}}} .
\end{gathered}
$$

As triangles $A O B$ and $A^{\prime} O B^{\prime}$ are similar,

$$
\begin{gathered}
\frac{A^{\prime} B^{\prime}}{A B}=\frac{A^{\prime} O}{A O}=\frac{B^{\prime} O}{B O} \\
A^{\prime} O=\frac{A^{\prime} B^{\prime}}{\tan \theta} \\
A O=\frac{A B}{\tan \theta} .
\end{gathered}
$$

$A^{\prime} O$ and $A O$ are the length $L$ and $A^{\prime} B^{\prime}$ are the stroke length $S$. So by adding these Eqs. ([7] + [8]), we get

$$
\begin{gathered}
L=\frac{A^{\prime} B^{\prime}}{\tan \theta}+\frac{A B}{\tan \theta} \Rightarrow \\
S=L \tan \theta-A B .
\end{gathered}
$$




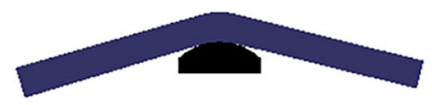

Under Bend

(a)

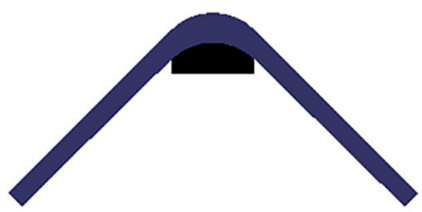

Full Bend

(b)

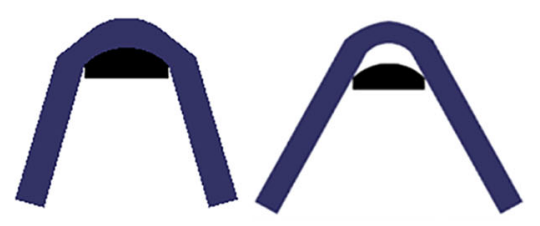

Over Bend

Fig. 7-Types of bends: (a) under bend which leads to under straining, $(b)$ desirable bend, $(c)$ over bend over straining.
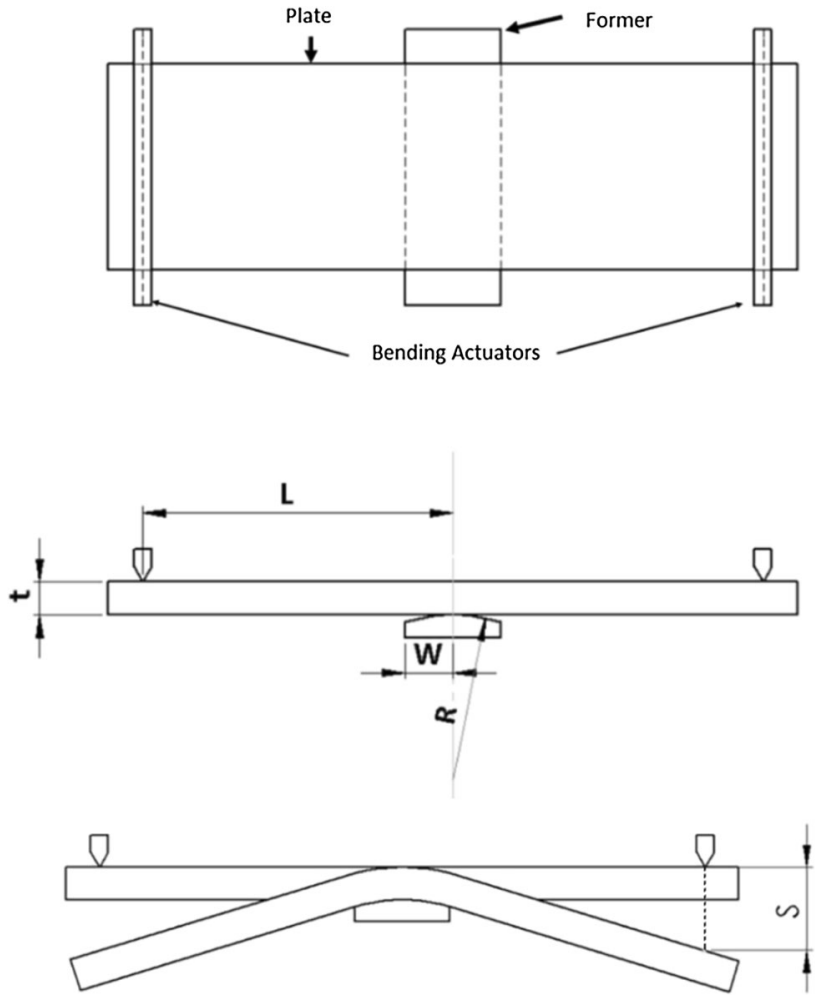

Fig. 8-Basic geometrical characteristics of a Trans-Varestraint test (where $L$, half-bending span; $t$, specimen thickness; $R$, former radius; $W$, former half-width; $S$, bend stroke).

For the triangle $D B C^{\prime}$,

$$
\begin{gathered}
\cos \theta=\frac{D C^{\prime}}{D B} \Rightarrow \\
\cos \theta=\frac{R}{R+A B} \Rightarrow \\
A B=\frac{R^{2}}{\sqrt{R^{2}-W^{2}}}-R .
\end{gathered}
$$

By substituting [13] through [10], we get

$$
S=\frac{L W}{\sqrt{R^{2}-W^{2}}}-\frac{R^{2}}{\sqrt{R^{2}-W^{2}}}+R \Rightarrow
$$

$$
S=\frac{L W-R^{2}}{\sqrt{R^{2}-W^{2}}}+R
$$

Equation [15] enables tests to be better defined and controllable. Each experiment has a defined bending stroke that needs to be applied in order to introduce a specific strain on the centerline of the setup.

For the Trans-Varestraint test, the weld bead should be applied at the centerline of the specimen. At a point where the welding process is stable, the bend should be applied. Each test has three phases (Figure 10). At time zero (point I), the welding process initiates and the welding bead starts being applied on the specimen at a fixed speed. Time two (point II) is when the bend will be applied and it is defined by the welding speed and the length from point I to point II. This can be calculated by Eq. [16].

$$
t_{\mathrm{II}}=\frac{\text { Distance between points I and II }}{\text { Welding Speed }} .
$$

After bending at point II, the welding process continues so that the solidification cracks have enough space to develop without being re-melted by the welding torch. If the welding torch remains in position during the bend, it will provide with enough energy for the material to be re-melted, thus providing with enough liquid metal to feed the voids that would be possibly be created from cracks. Also, by continuing the welding process the solidification of the material is allowed to continue while the augmented strain is applied. Recent research has estimated that solidification cracks propagate at a speed between 2 and $3 \mathrm{~mm} / \mathrm{s}^{[15]}$ Therefore, for a weld bead of depth 2 to $3 \mathrm{~mm}$ and a welding speed of $3 \mathrm{~mm} / \mathrm{s}$ the welding process should continue for at least 1 second after the bend. In the present study, the welding process continued for 2 seconds after the bend to ensure this criterion was met. When point III is reached, the welding process stops.

\section{B. Experiment Design}

The specimens used for the tests were plates of X65 and EN3B steel (composition given in Table I) with dimensions of $500 \times 150 \times 24 \mathrm{~mm}$. 


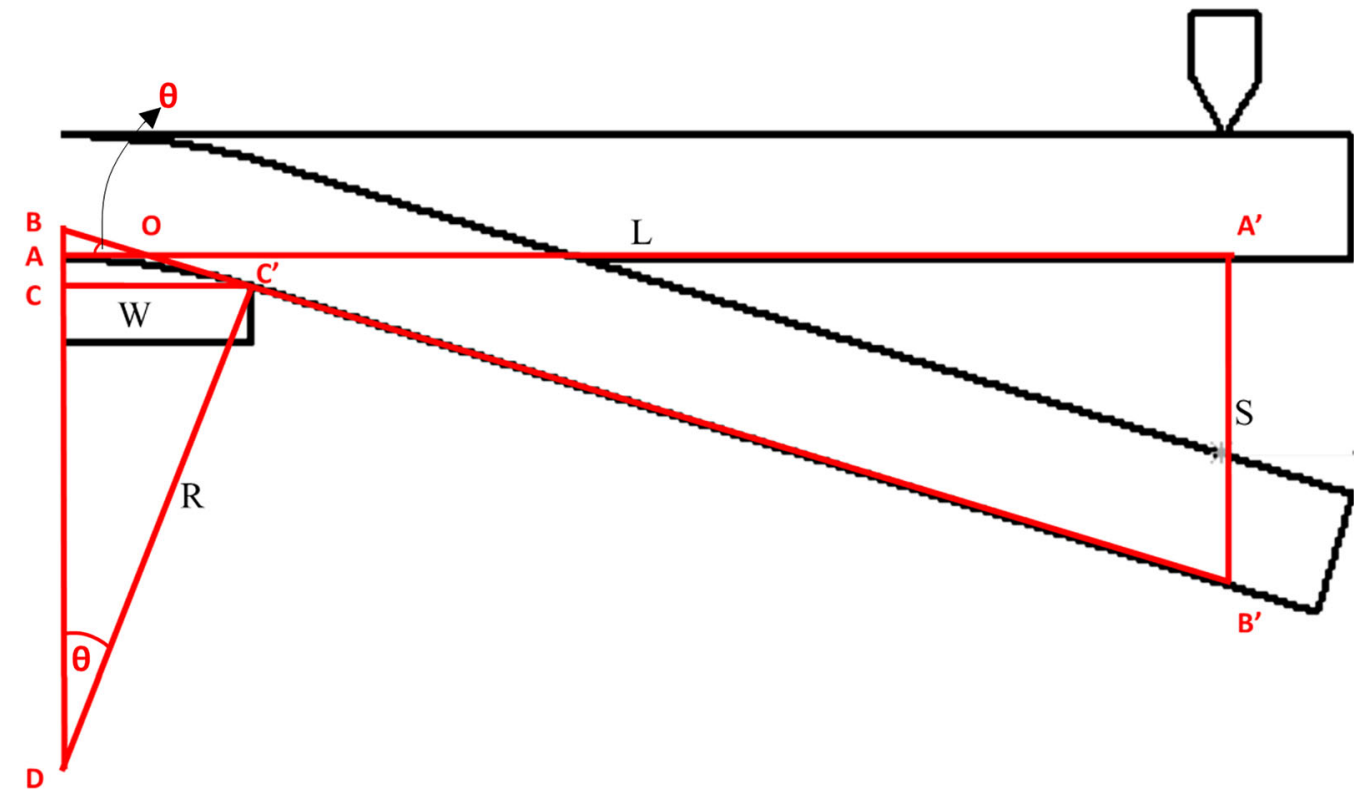

Fig. 9-Relevant geometry of bending setup.

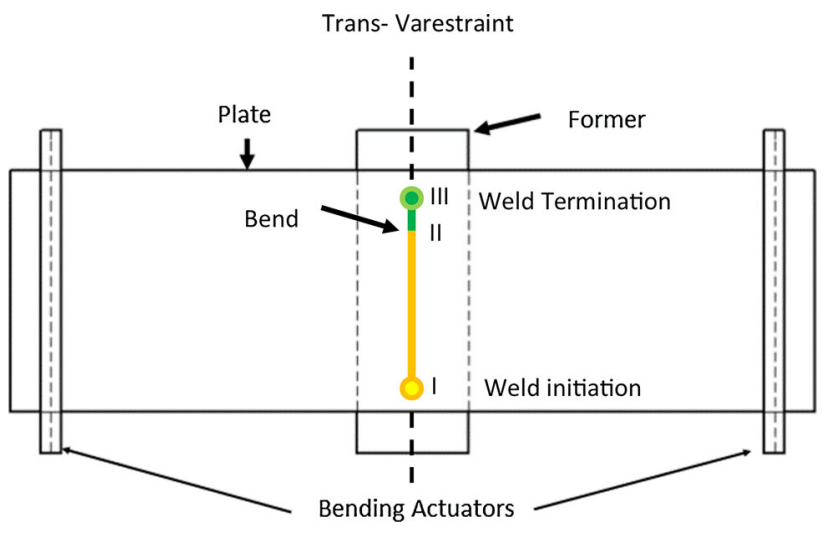

Fig. 10-Trans-Varestraint test setup.

To validate the method described, a series of eight tests were conducted with target augmented strains between 2 and 11 pct. Eight different formers were manufactured (Table II) to control the radius of the bend, with radii determined by the equation for augmented strain [1].

A custom made Trans-Varestraint rig (Figure 11) was used in the present study. The rig consists of a base on which the formers are placed. The specimen rests on the former with the moving actuators, powered by a hydraulics unit, positioned on either side. The welding torch is suspended from a traversing system that moves at a specified speed that is fixed during the experiment.

A strain gauge was set $10 \mathrm{~mm}$ from the long edge of the plate near the initiation point of the welding process (as seen in Figure 11). For the augmented strains below 5 pct., Kyowa KFG-5-120-C1-11L1M3R strain gauges were used. For the augmented strains above 5 pct, high-elongation strain gauges (Kyowa KFEL-5-120-C1-L1M3R) were used. Strain gauges were used during the first series of experiments on X65 steel in order to confirm that the augmented strain that the method predicts will be the one applied during the experiment. Using the method, described at the end of section 0 , tests for the required combinations of strain and stroke length were carried out (Table II).

Tungsten inert gas (TIG) welding carried out autogenously (no filler wire) in the negative polarity $(-\mathrm{ve})$ : welding speed, $3.5 \mathrm{~mm} / \mathrm{s}$; amperage, $225 \mathrm{~A}$; voltage, 12 $\mathrm{V}$; Argon was used as a shielding gas at a flow rate of 8 $\mathrm{L} / \mathrm{min}$. Welding was initiated at the start of each test, 30 $\mathrm{mm}$ from the long edge of the plate, and continued for 25 seconds after which it was terminated. To ensure that the welding process reached a quasi-steady state at the time of the bend and that enough material was left for the welding process to continue, after the bending of the plate, the bending process was initiated at a time of 23 seconds. One specimen was bent without welding in order to verify that the strain applied, using the described method, was the intended strain. For that experiment, data were obtained from 4 strain gauges placed on a plate (Figure 12).

This test was carried out because it was not possible to place strain gauges (because of the heat of the weld) close to the point where the cracks would appear during the test. For the welding tests, only one strain gauge could be placed and the position was as close to the weld as was tolerable given the heat (see Fig. 11).

\section{Post-Experimental Process}

After tests were carried out, the specimens were collected, the welding beads were cleaned using methanol, and the specimens were photographed (Figure 13). Cracks were then identified and imaged using an Ash Inspex HD 1080p digital microscope. 
Table I. Chemical Composition Limits of X65 Steel ${ }^{[33,34]}$

\begin{tabular}{lllllll}
\hline $\begin{array}{l}\text { Grade } \\
\text { Class }\end{array}$ & and & & & & & \\
X65 PSL 1 & $0.26(\max )$ & $1.40(\max )$ & - & $0.030(\max )$ & $0.030(\max )$ & the sum must not exceed 0.15 pct \\
EN3B & 0.16 to 0.24 & 0.50 to 0.90 & $0.35(\max )$ & $0.05(\max )$ & $0.05(\max )$ & \\
\hline
\end{tabular}

Table II. Radii of Bending Formers, Stroke Length, and Specimen Codes According to Augmented Strain

\begin{tabular}{lccc}
\hline Augmented Strain $($ Pct) & Former Radius $(\mathrm{mm})$ & Stroke Length $(\mathrm{mm})$ & Specimens \\
\hline 2 & 600 & 14 & TVA 2.1, TVA 2.2, TVA 2.3 \\
3 & 400 & 20 & TVA 3.1, TVA 3.2 \\
4 & 300 & 27 & TVA 4.1, TVA 4.2, TVA 4.3 \\
6 & 200 & 40 & TVA 6.1, TVA 6.2, TVA 6.3 \\
8 & 150 & 54 & TVA 8.1, TVA 8.2, TVA 8.3 \\
9 & 133 & 61 & TVA 9.1, TVA 9.2 \\
10 & 120 & 69 & TVA 10.1, TVA 10.2, TVA 10.3 \\
11 & 109 & 76 & TVA 11.1, TVA 11.2 \\
\hline
\end{tabular}
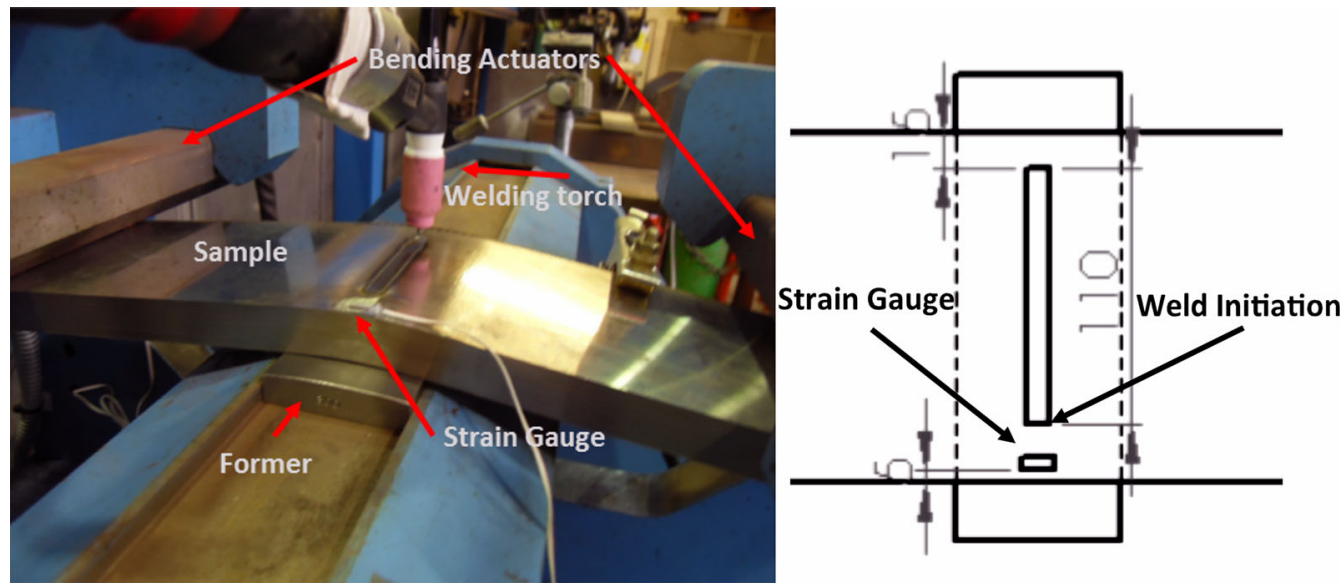

Fig. 11-Experimental setup for Trans-Varestraint test.
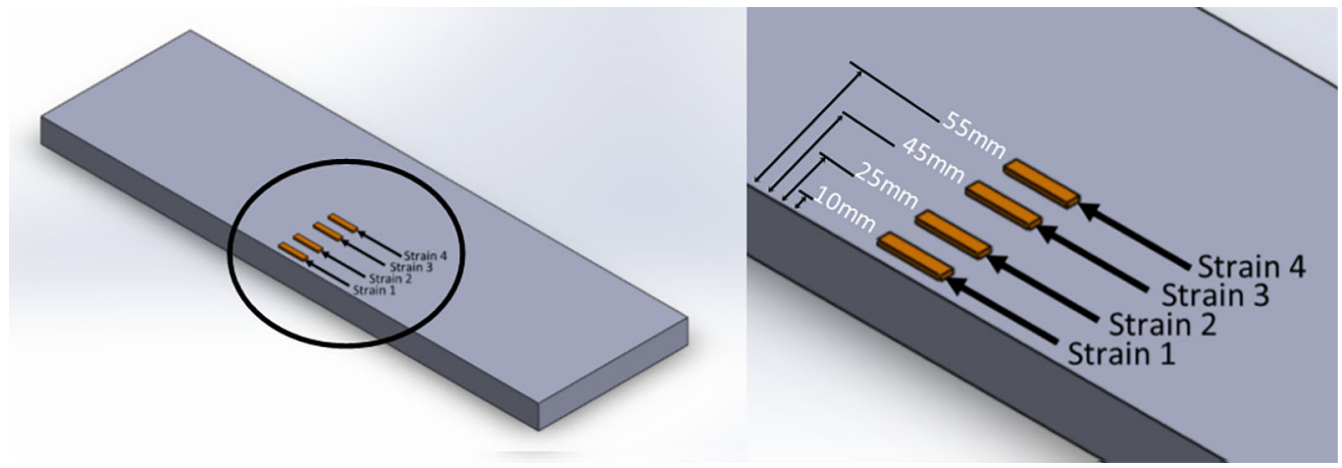

Fig. 12- Strain gauge positions on plate for the experiment where the bend is applied without welding. 


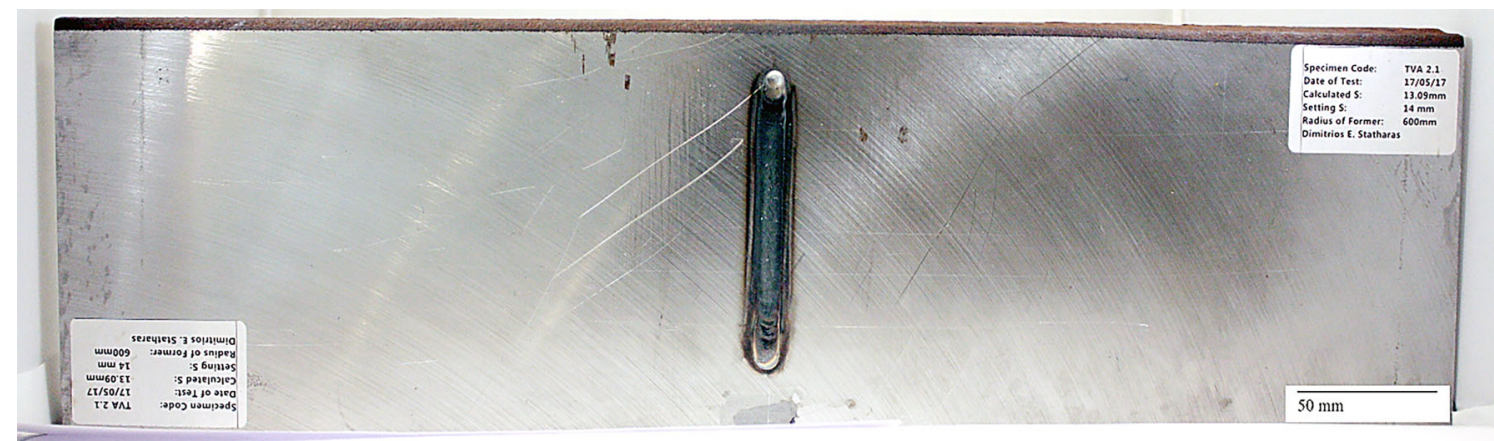

Fig. 13-Specimen TVA 2.1 (2 pct strain applied).

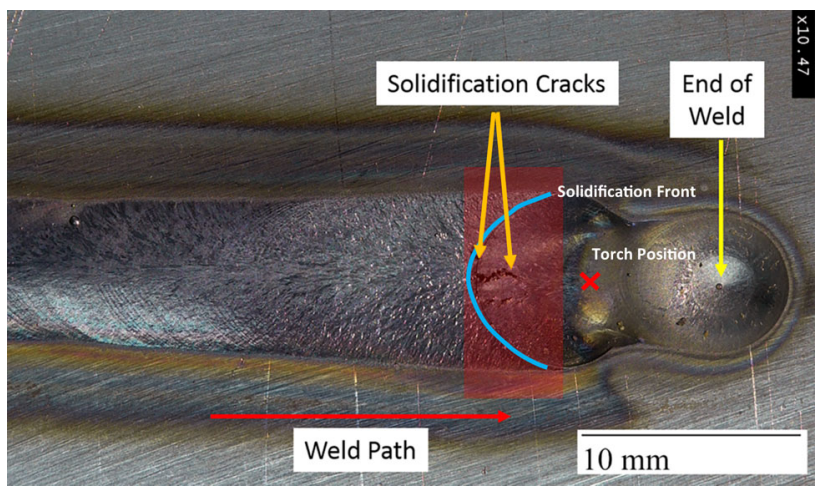

Fig. 14-Identification of solidification cracks, area to be examined using X-ray CT (TVA 10.1: 10 pct augmented strain X65 steel) highlighted in red, crack initiation on the solidification front trailing the welding torch.

The cracks on each specimen were measured using Image J software. Individual cracks, on the surface of the weld, were identified and individually measured (Figure 14).

For each specimen, maximum crack length (MCL) and total crack length (TCL) values were determined. (Note that MCL is equal to maximum crack distance (MCD) in Trans-Varestraint tests as explained in Figure 2).

Non-destructive testing (NDT) using liquid dye penetrants was then carried out to ensure that cracks, which could not be identified using a stereoscope, were identified. The NDT required the use of a remover spray (to clean the surfaces before and after the tests), a penetrant and, finally, a developer to reveal the indications of any crack.

After the NDT was carried out, the samples were sectioned in order to perform X-ray CT (XRCT) scans for three-dimensional sub-surface crack imaging and measurement. The steel specimens were sectioned so that their thickness would be less than $10 \mathrm{~mm}$. As the volume in which cracks develop is limited to a specific point of the welds (see Figure 14 above), extracting small enough samples for XRCT is feasible. The following figure (Figure 14) highlights the area that was extracted from the specimens. The thickness of these samples was between 3 and $4 \mathrm{~mm}$.
A Nikon Metris X-TEK XT H 225 CT scanner was used with a rotating tungsten target and a 1-mm copper filter. The beam had an accelerating voltage of $150 \mathrm{kV}$ and a current of $170 \mu \mathrm{A} .1500$ projections, each with a 2 -second exposure, were acquired during each scan with the option to minimize what are called 'ring artifacts' enabled. Reconstruction of the scans was carried out using Nikon CT Pro 3D software.

After XRCT was carried out, specimens were quenched in liquid nitrogen and fractured in order to expose the cracks. Quanta 650 FEG scanning electron microscope was used to examine the fracture surfaces, using a voltage of $20 \mathrm{keV}$ and spot sizes between 5.0 and 6.0 .

\section{RESULTS}

From the experiments on X65 steel, cracks were observed from applied augmented strains of 3 to $11 \mathrm{pct}$, with no observable cracks at 2 pct strain. Both the maximum crack length (MCL) and total crack length (TCL) were recorded (Figure 15), with the MCL correlating with the crack evolution previously reported and illustrated in Figure 4.

The results of the cold bend experiments (Figure 16) demonstrate the importance of control of the stroke length during Trans-Varestraint experiments. The maximum strain recorded was always greater than the intended strain. The strain near the edge was greater because of the near edge effects (Poisson's ratio) during bending that allowed for the plate to contract in those regions. The cold bend test indicated that further from the edge of the specimen the strain decreased. Additionally, particularly in the edge region an overshoot from the desirable stroke was observed. This was followed by a spring back that occurred when the force ceased to be applied due to the elastic component of the strain in the plate at the end of the bend.

By examining the results further towards the center of the plate where the welding process is taking place and where cracks are generated, the strain is significantly lower (near strain gauge 3 as seen in Figure 16). The results also indicate that the use of the equation, which has been suggested for this method, will provide with a stroke length that will ensure that the required strain 


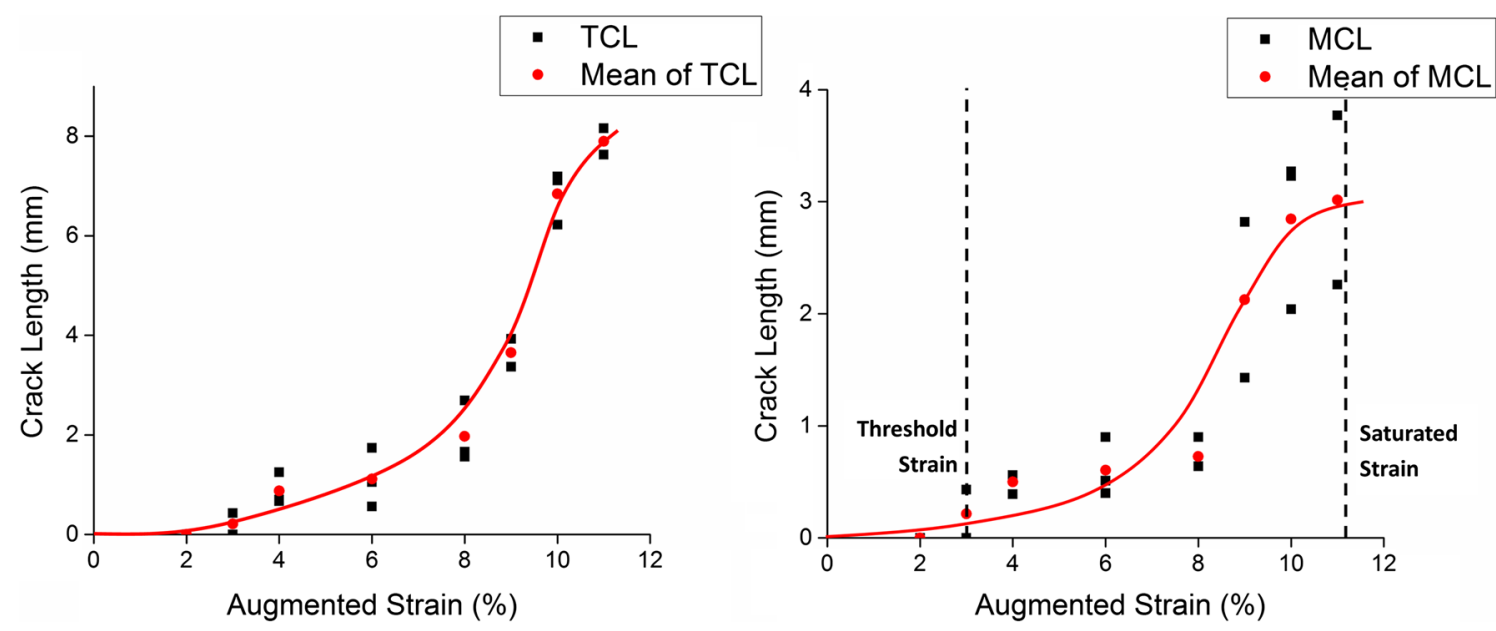

Fig. 15-Total crack length (TCL) vs Augmented Strain and maximum crack length (MCL) vs Augmented Strain for comparison (X65 steel). Maximum crack length values indicated by red line illustrate how the evolution of cracks is expected according to Fig. 4.

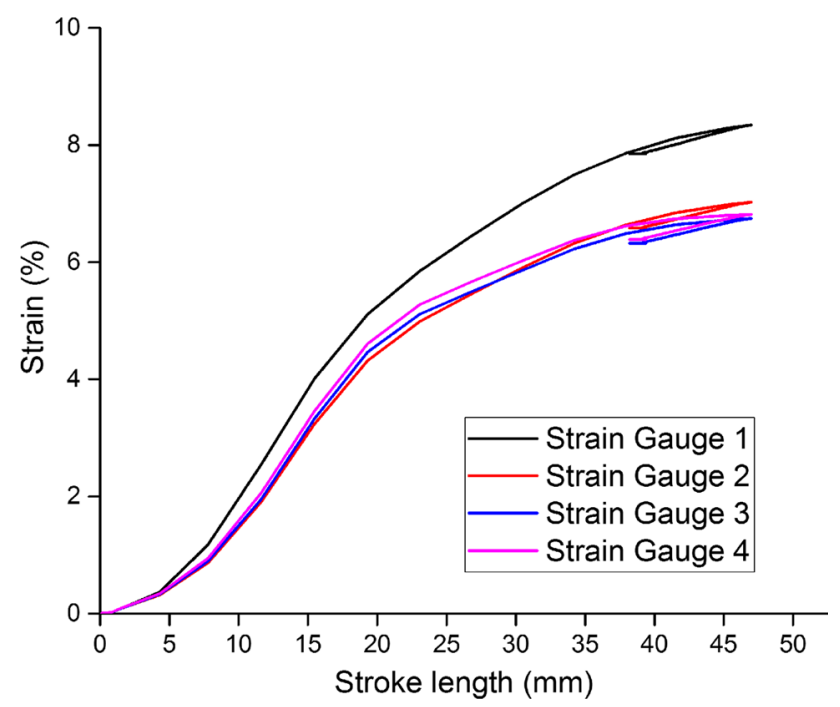

Fig. 16- Strain development during cold bending of plate at 6 pct target augmented strain. (X65 steel).

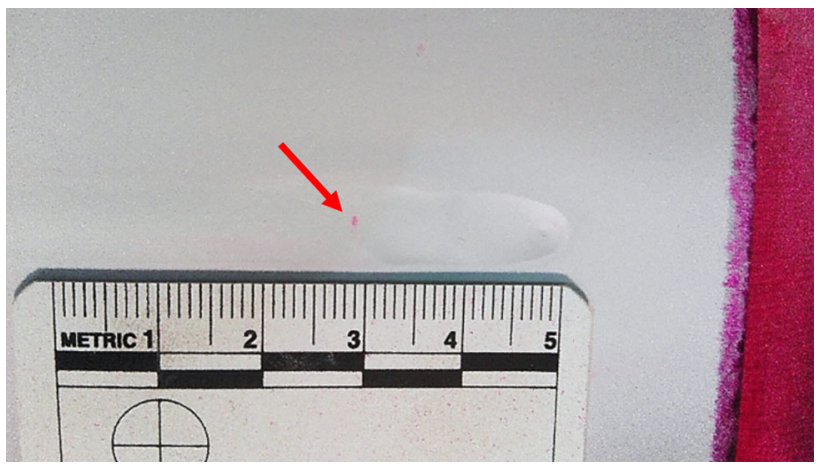

Fig. 17-Dye penetrant Indication on sample TVA 2.3 (X65 steel) where no cracks were observed during stereoscopic examination.

will be applied on the centerline of the plate. In this case, the desired strain was 6 pct and the stroke length calculated was $39 \mathrm{~mm}$.
The results of NDT on the plate where 2 pct augmented strain was applied (Figure 17) indicated that small surface cracks can occur during Trans-Varestraint tests, which are difficult to detect by stereoscopic examination.

The Trans-Varestraint experiments indicate that cracks initiate at a position trailing the welding torch (Figure 14) and evolve from the solidification front, towards the heat source, as the material solidifies. This was confirmed by XRCT scans that revealed that the cracks initiate on and follow the solidification front (Figure 18).

The maximum crack depth was recorded for all the specimens that were scanned. The scans revealed that even when 2 pct strain was applied (and no cracks were observed in the surface of the weld) sub-surface cracks were present. All the cracks measured had the same maximum crack depth, approximately $1.4 \mathrm{~mm}$ from the weld surface, except in the 2 pct strained specimen, where the crack depth was approximately $0.9 \mathrm{~mm}$ (Figure 19).

These results demonstrate that hot cracks initiate below the surface and, once a maximum depth is reached, the amount of strain imposed will not affect it. The measurements also indicate a connection between the maximum depth of cracks and the threshold strain presented in Figure 15. By comparing the cracks developed in a high-strain specimen compared to a low-strain specimen (TVA10.1 and TVA2.1, Figure 20), it was observed that cracks tend to initiate on the solidification front where its angle relative to the surface is $45 \mathrm{deg}$.

In order to probe further into these indications, the hot cracks generated from the experiment were examined under a FEG-SEM (Figure 21).

By focusing on the inter-dendritic stage 3 fracture, which originates from the crack initiation point that was identified by the XRCT scans, it was observed that the dendrites have a preference in orientation that forms a 45 deg angle with the surface of the sample (Figure 21). By following these structures to their origin, the depth measured was approximately $0.9 \mathrm{~mm}$. This indicates 


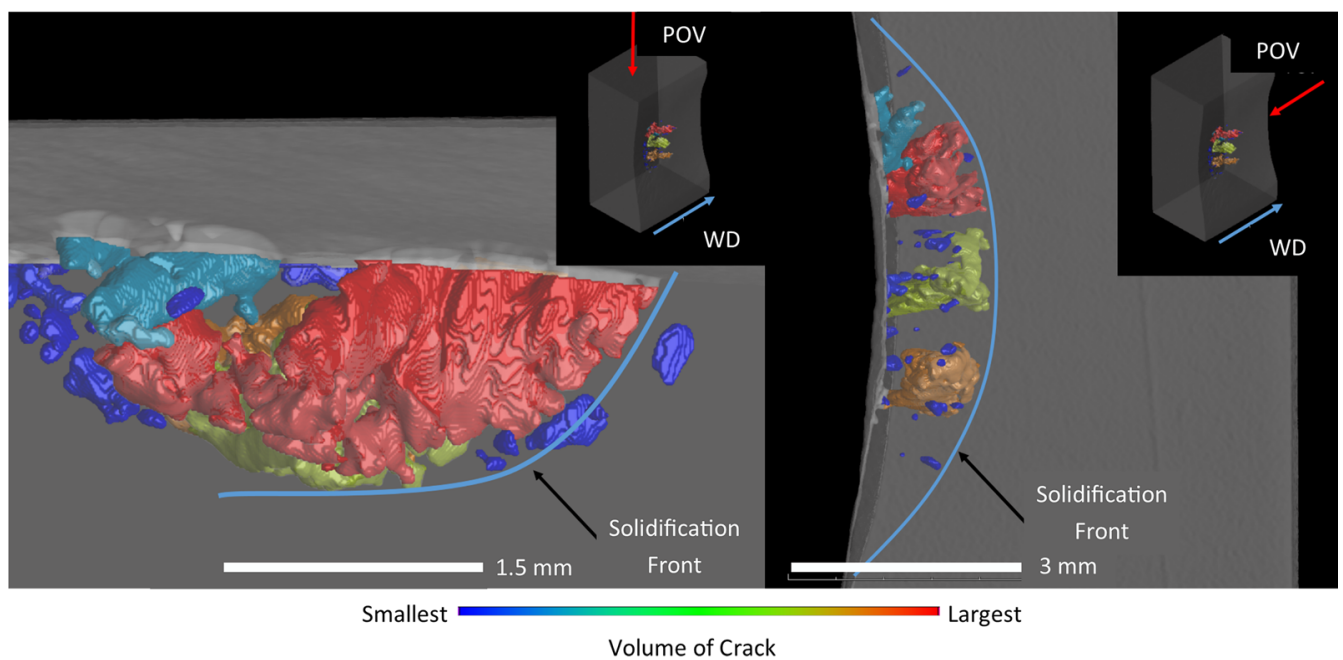

Fig. 18- Specimen TVA 11.1 (augmented strain: 11 pct, X65 steel) crack pattern follows solidification front of weld (WD = welding direction, $\mathrm{POV}=$ point of view).

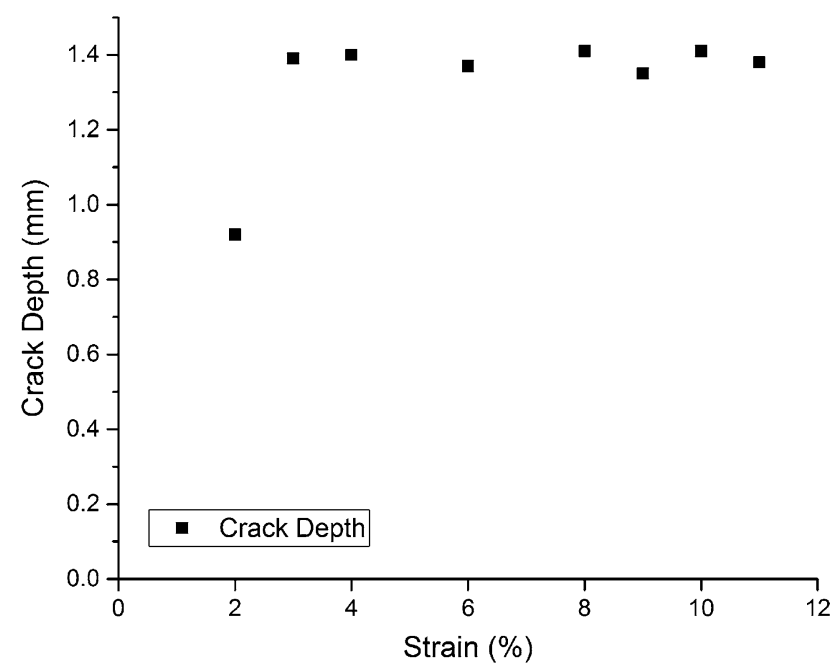

Fig. 19-Maximum crack depth for Trans-Varestraint test specimens of X65 steel.

that there is a connection between the initiation point of the cracks and the angle that is formed by the solidification front and the surface of the weld.

A second series of Trans-Varestraint tests was carried out on EN3B steel - a type of steel that can be welded but is strongly susceptible to hot cracks. Crack lengths were recorded and compared to the ones for the X65 steel, as shown in Figure 22. The results made clear that both materials follow the crack evolution trend illustrated in Figure 4 but EN3B reached the threshold condition and started exhibiting cracks at much smaller augmented strains than X65.

\section{DISCUSSION}

\section{A. Ensuring Test Repeatability}

The Trans-Varestraint rig, used in this study, was designed to apply the maximum possible stroke length during the test and hold the plate at that position to eliminate spring back. However, the method presented requires different stroke lengths to allow for the variation of the applied strain. Under these conditions, the hydraulics unit would not hold the actuators in place and so a small amount of spring back was inevitable. Additionally, due to the inertia of the rig, the target stroke was systematically exceeded. Despite these limitations, the method was still controllable and repeatable since both the spring back and overshoot were consistent in each experiment (Figure 23). Specifically, these were found to be $-1.11 \pm 1.30$ and $6.62 \pm 1.16$ $\mathrm{mm}$, respectively, which can therefore be compensated for in future experiments. Adding to that, because the strains applied for this experimental process are extreme, these variations would not significantly affect the applied strain. Furthermore, the welding process continued for 2 seconds after the bending process. During this time (after the spring back), the specimens were close to the target stroke. This means that momentarily the augmented strain applied on the weld was slightly higher than the target.

\section{B. Reliable Application of Augmented Strain}

For the standardization of tests, reliability and repeatability must be demonstrated and verified by multiple investigators. With Varestraint and Trans-Varestraint tests, this has not yet been achieved due to the variety of welding procedures and test rigs that have been used in the published literature. These include cantilever, mandrel, and three-point bend designs. ${ }^{[30-32,35,36]}$ It is further worth noting that the alignment of the bending plane of the specimen, the axis of any former (if used), and the weld bead (and therefore the solidification front) is also critical as the strain varies significantly away from the bending plane of the specimen. This was verified through both strain gauge data from the cold bend experiment (Figure 16) and by simulation, using the CAE software ABAQUS, to replicate the bending process (Figure 24). In summary, 


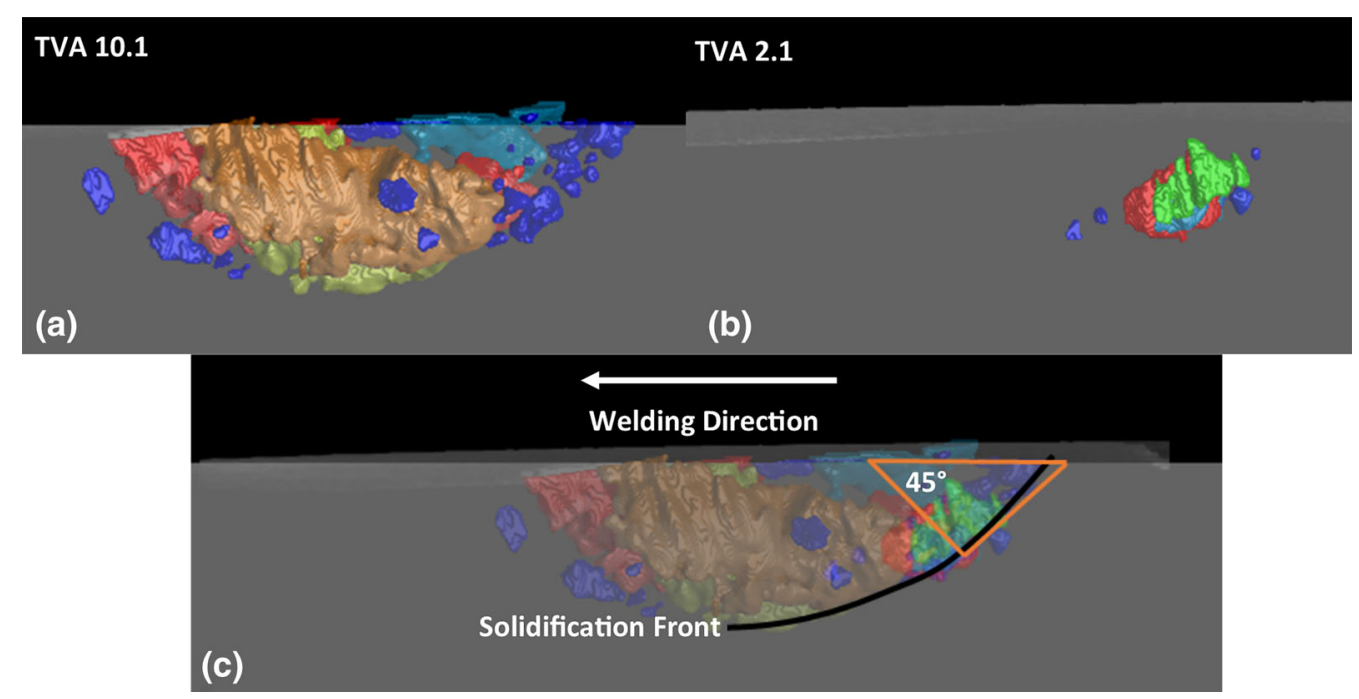

Fig. 20 - Comparison of hot cracks: (a) 10 pct strain specimen; (b) 2 pct strain specimen; $(c)$ overlay of the two specimens, illustrating that cracks initiate on the solidification front where its angle with the surface of the specimen is $45 \mathrm{deg}$.

previous methods have lacked accurate control of the applied strain to the weld bead.

By using formers of a prescribed radius (Eq. [1]), a controlled stroke length (Eq. [15]), and consistent time of bend, these factors have been addressed in the present study.

\section{Measurement of Hot Crack Susceptibility}

It was observed that the maximum crack length (MCL) values better fit the theoretical evolution of crack length vs strain (illustrated in Figure 4) than the total crack length (TCL) values (Figure 15). While the MCL values appear to reach a state of saturated strain, the TCL values do not provide evidence of saturation.

Comparative tests between X65 steel and EN3B steel, using the method presented, demonstrated that differences in susceptibility can be defined by the MCL parameter. While EN3B initially presented cracks at 1 pct augmented strain with a mean length of $0.5 \mathrm{~mm}$, X65 initially presented cracks at 3 pct augmented strain with a mean length of $0.25 \mathrm{~mm}$. Furthermore, EN3B exhibited an MCL value greater than that for X65 and reached the saturation point at lower augmented strain. These results demonstrate that EN3B is more susceptible to hot cracking than X65, as expected.

\section{Evolution of Hot Cracks}

The results from NDT (Figure 17) and XRCT (Figures 18,20) demonstrated that optical surface crack measurements alone are insufficient for the purposes of defining hot crack susceptibility. During hot cracking, cracks first initiate on the solidification front, where the tangent of the solidifying material makes an angle of $45^{\circ}$ with the surface (Figure 20). This was highlighted by the observation of sub-surface cracks at a 2 pct augmented strain, where no surface cracks were visible.

It is argued that, as the tests that have been described have been carried out such that control of the strain is repeatable and reliable, each specimen can be considered as a snapshot of the various stages of crack initiation and evolution. The observation of cracks forming, in the 2 pct strain specimen on the tangent of the solidification front that made an angle of $45 \mathrm{deg}$ to the surface, can be explained as this is the point where the maximum shear stress on the solidifying material exists. This is further supported by observations that showed the solidification direction being perpendicular to the solidification front (Figure 21).

A mechanism for hot crack initiation is therefore proposed. Along the centerline of the welding bead, dendrites start to form in the direction of the heat source (i.e., the welding torch). During the Trans-Varestraint test, the augmented strain results from the combination of the shrinkage strain due to solidification and the mechanical strain imposed by the bending action of the test. ${ }^{[25]}$ The strains applied from the test are tensile perpendicular to the plane in which the axis of the welding bead lies.

During this application of strain, welding and solidification is still under development and due to the nature of the shape of the weld pool there is bound to be a section of the solidification front that will create an angle of $45 \mathrm{deg}$ with the surface of the weld. As solidification is still taking place at the point where the greatest shear stress/strain is being applied, dendrites are being pulled apart creating voids which result in initiation of cracks. 


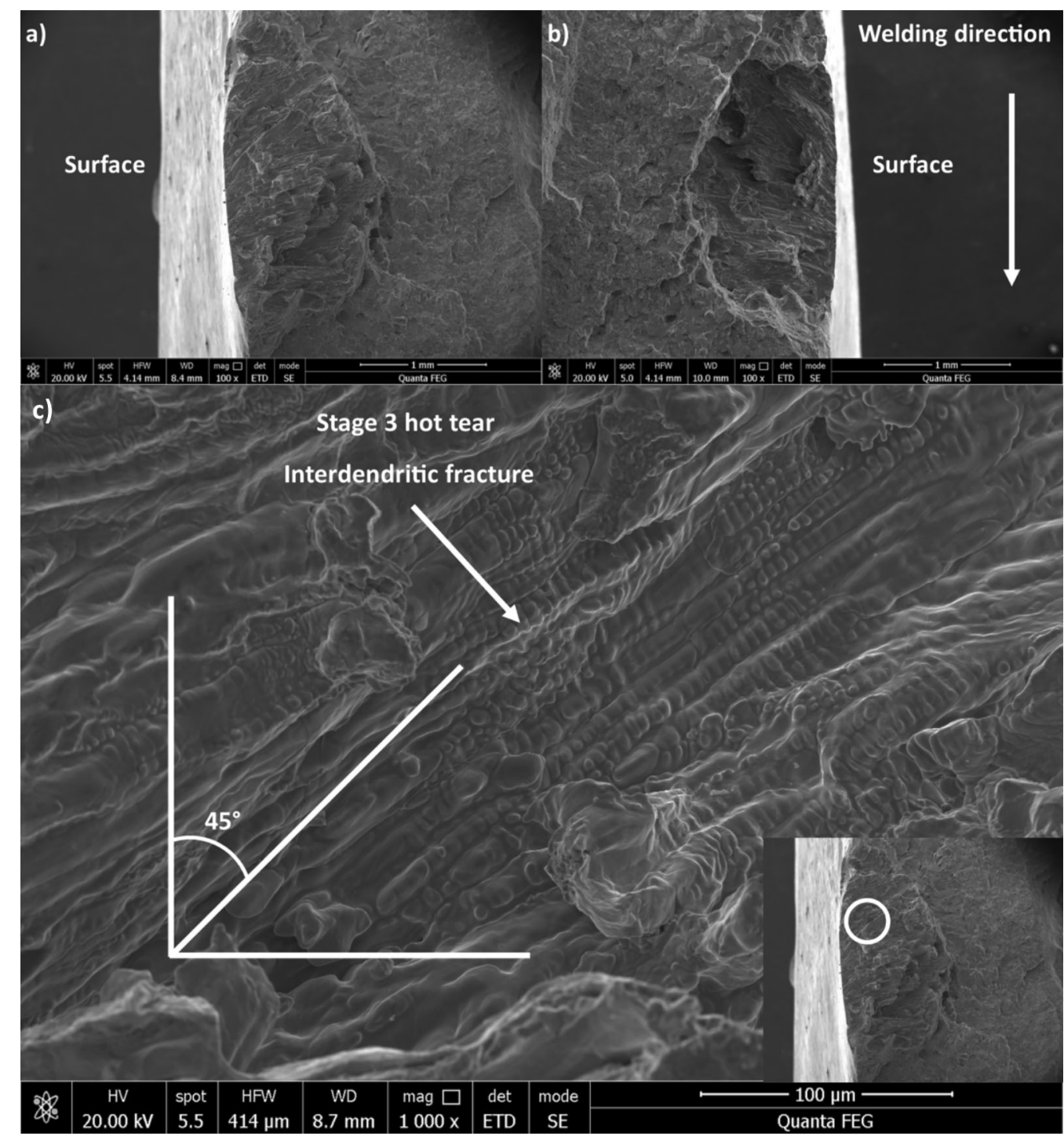

Fig. $21-(a, b)$ General view of both sides of a hot crack from a TVA specimen (TVA 10.1, augmented strain 10 pct, X65 steel). (c) Stage 3 hot cracking near the surface of the weld pool indicating clear preference in the orientation of the dendrites at an angle of $45^{\circ}$ with the surface of the weld.

The observation of this crack initiation point is supported by analytical modeling based on Rosenthal's equations. ${ }^{[37]}$ By employing Rosenthal's solution for the temperature gradients for thick plates, a realistic approximation of the welding bead that has been used for the experimental process was achieved. The model (Figure 25) illustrates that the depth at which crack initiation was observed matches with a small range of depths that the tangent of the solidification front is expected to form an angle of $45^{\circ}$ with the surface.

\section{E. Significance of Findings}

The lack of standards for hot cracking susceptibility prevents reliable evaluation of candidate materials and development of further understanding of the hot cracking phenomenon. ${ }^{[29,38,39]}$ The experimental work, reported in this study, demonstrates a method for Trans-Varestraint testing that is more repeatable and reliable than reported in the previous literature.

In combination with the results of published research, ${ }^{[13-15,29,32,38-46]}$ the method presented could form the basis of standardized Trans-Varestraint tests. 
The results reported also identify a range of 'critical' depths where hot cracks initiate, which correlates with the dendrite growth orientation and maximum shear stress location.

These findings may therefore be applied in future welding simulations to predict crack initiation and hot crack susceptibility in a wide range of materials, which would be a valuable predictive tool for both further academic research and industrial application. In the latter case, such a standardized testing approach may result in a database of materials with a parameter quantifying their hot cracking susceptibility.

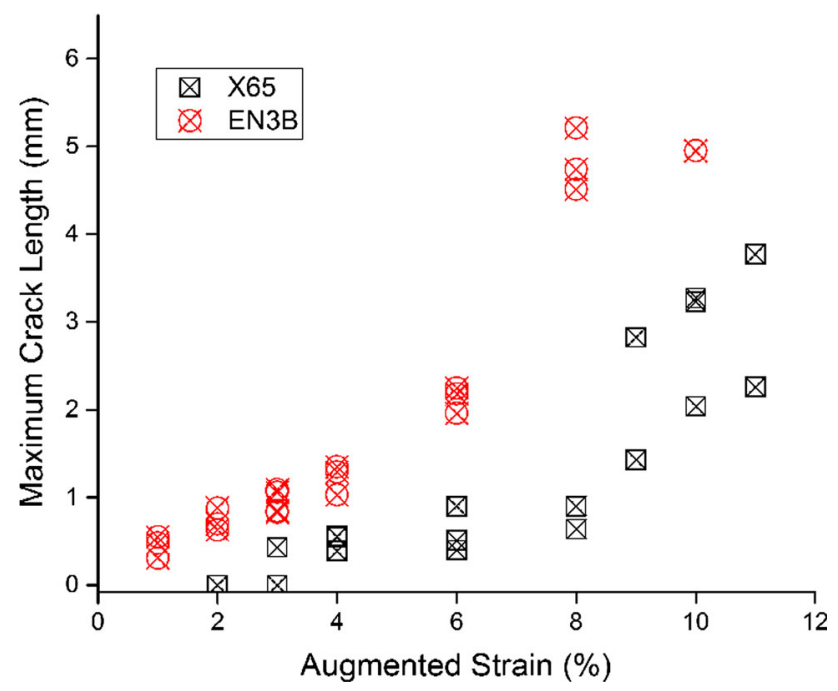

Fig. 22-Comparison of maximum crack length between EN3B steel and X65 steel.

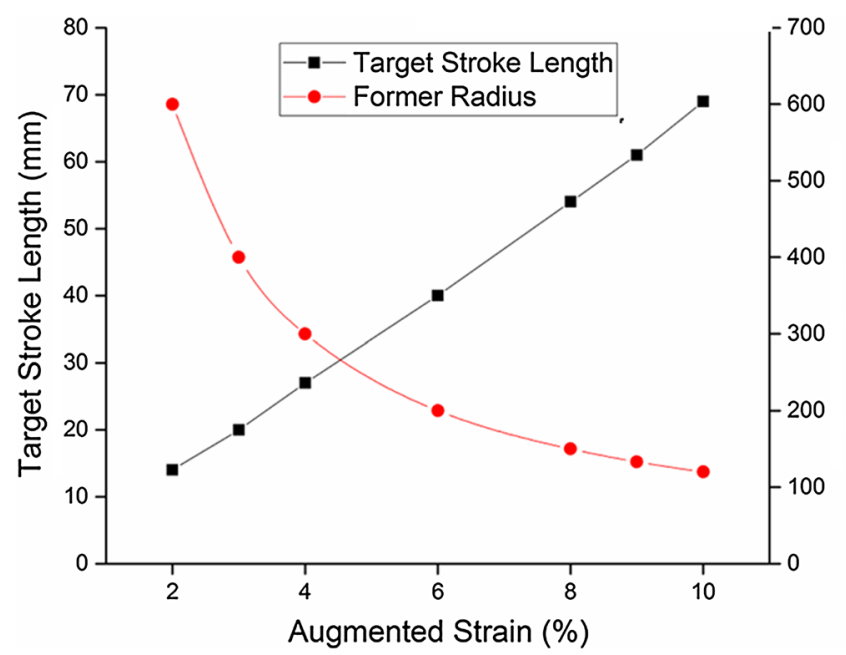

Fig. 23-Comparison of stroke lengths for each experiment.

\section{F. Limitations}

The method presented provides solutions to control several critical aspects of Trans-Varestraint testing. However, while the reported method allows for the precise control of strain applied, it does not provide a solution to control the strain rate. It has been reported that strain rate can affect the generation of hot cracks given that two columnar grains growing side by side can potentially grow towards each other and bond together in order to resist cracking as long as they are being pulled apart by tension more slowly than the rate of bonding. ${ }^{[47,48]}$ Additionally, the maximum stroke, which the rig in the present study was able to apply, was 80 $\mathrm{mm}$. It was therefore not possible to apply augmented strains above 11 pct. From the results obtained (Figure 15), the saturation point of X65 remains unclear. Hence, the reported method requires equipment capable of applying high augmented strains in order to be capable of defining the point of hot crack susceptibility for materials with high resistance to this phenomenon.

\section{CONCLUSIONS}

The reported study demonstrated that by utilizing the presented method:

- The augmented strain applied during the Trans-Varestraint tests can be controlled accurately and reliably, using the experimental methodology applied in the present study. This will allow tests that are conducted using experimental setups similar to the one described to be comparable.

- The effect of the strain rate can now be studied as the experimental methodology in the present study allows for accurate control of the augmented strain.

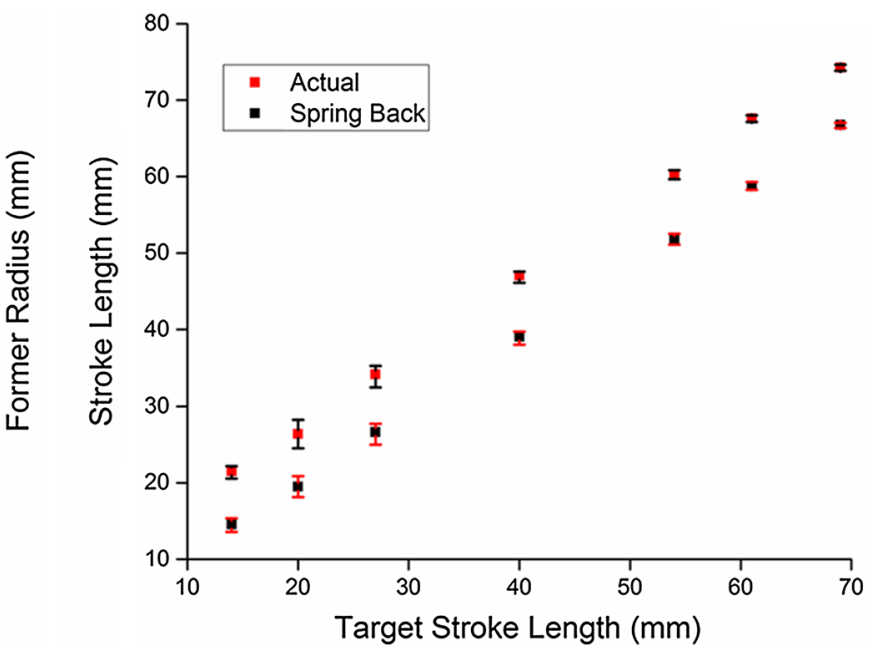




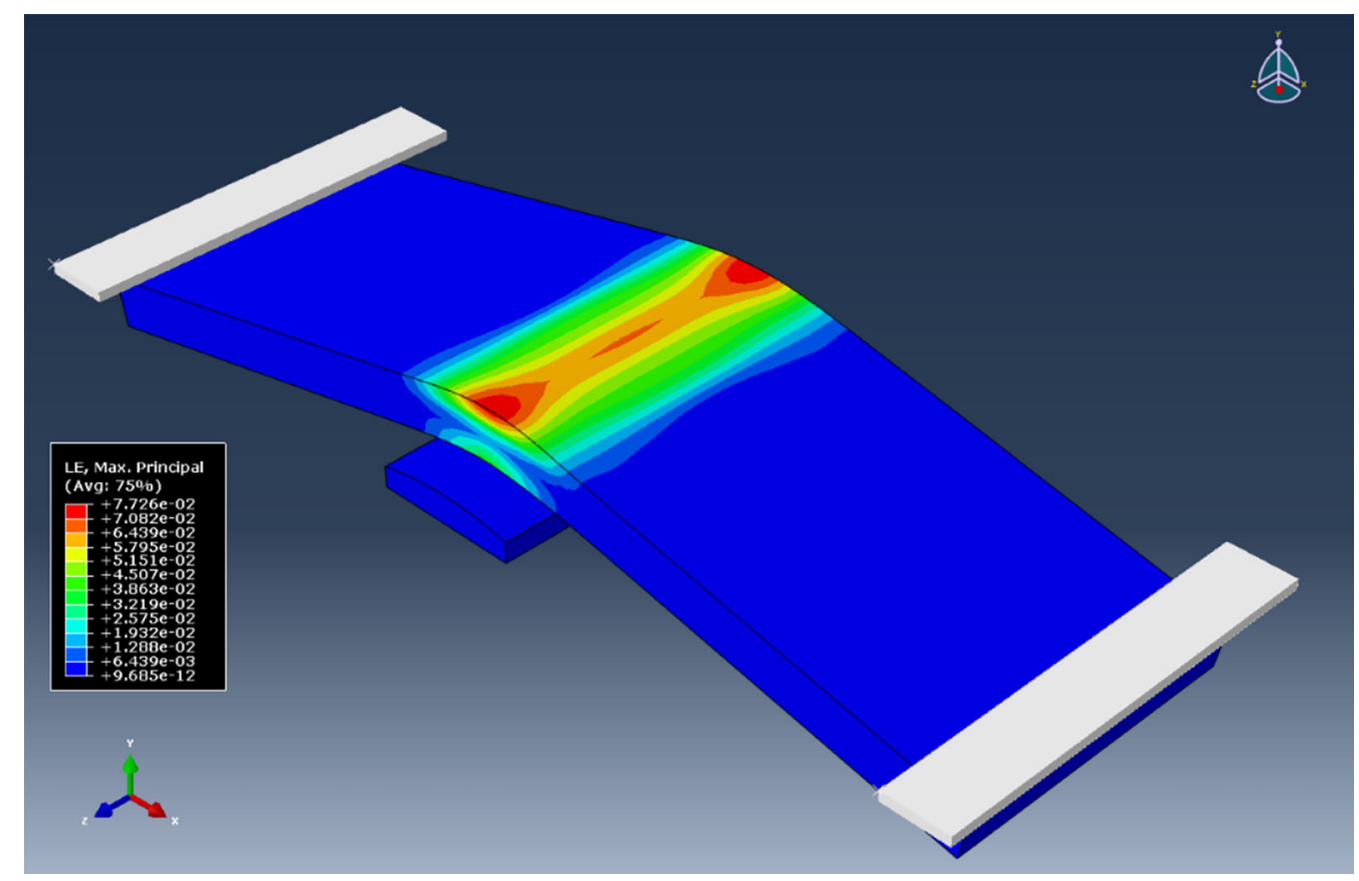

Fig. 24-ABAQUS results that replicate cold bend test. Strain along the centerline is highest (red/orange) and drops away from the centerline (yellow/green/blue) (Color figure online).

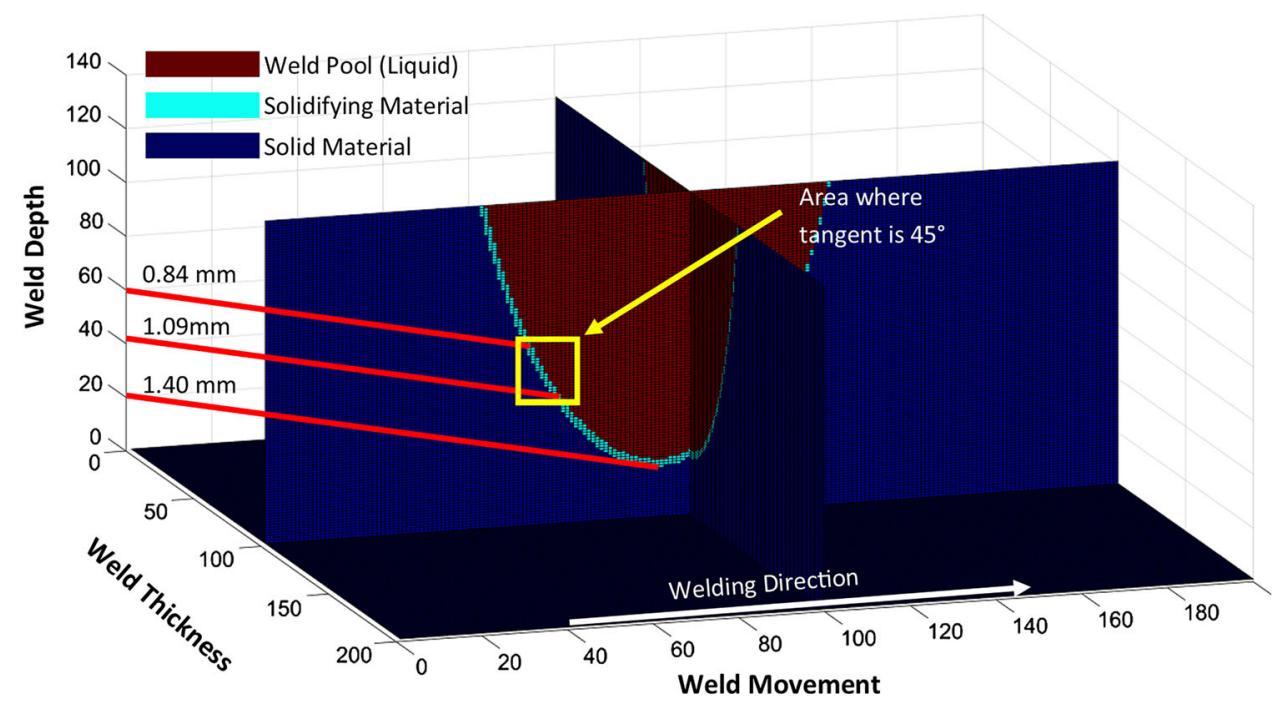

Fig. 25-MATLAB R2015a solution to an analytical welding model based on Rosenthal's equations indicating the depth where the tangent of the solidification front is $45 \mathrm{deg}$.

- It can be confirmed that EN3B is significantly more susceptible to hot cracking than X65 since it constantly presents a MCL higher than that for $\mathrm{X} 65$ at lower augmented strains, $0.5 \mathrm{~mm} \mathrm{MCL}$ at 1 pct augmented strain $v s 0.25 \mathrm{~mm}$ MCL at 3 pct strain, respectively.
- Examination of the hot cracks under SEM revealed that the orientation of dendrites that originate from the crack initiation points has a 45 deg angle with the surface of the weld.

- This observation of dendrite orientation at the crack initiation points, in combination with an analytical 
model, may allow for initiation sites of hot cracks during welding to be predicted as the point where the solidifying material experiences the maximum shear.

\section{ACKNOWLEDGMENTS}

The authors wish to acknowledge the support for this study that was provided by the Center for Doctoral Training in Innovative Metal Processing (IMPaCT), at the University of Leicester, funded by the UK Engineering and Physical Sciences Research Council (EPSRC), Grant Reference EP/L016206/1. The authors would also like to acknowledge Mr Graham Clark and the Mechanics of Materials Laboratory (Department of Engineering, University of Leicester) for their significant help with the XRCT imaging. Raw data relating to this publication is available under https://doi.org/10.25392/leicester.data.c. 4389710 .

\section{OPEN ACCESS}

This article is distributed under the terms of the Creative Commons Attribution 4.0 International License (http://creativecommons.org/licenses/by/4.0/), which permits unrestricted use, distribution, and reproduction in any medium, provided you give appropriate credit to the original author(s) and the source, provide a link to the Creative Commons license, and indicate if changes were made.

\section{REFERENCES}

1. A. Bochvar, N. Rykalin, N. Prokhorov, I. Novikov, and B. Movchan: Weld. Prod., 1960, vol. 10, pp. 5-7.

2. N. Prokhorov and N.N. Prokhorov: Trans. Jpn. Weld. Soc., 1971, vol. 2 , pp. $205-13$.

3. T. Senda, F. Matsuda, G. Takano, K. Watanabe, T. Kobayashi, and T. Matsuzaka: Trans. Jpn. Weld. Soc., 1971, vol. 2, pp. 141-62.

4. Y. Arata, F. Matsuda, H. Nakagawa, S. Katayama, and S. Ogata: Trans. JWRI, 1977, vol. 6, pp. 197-206.

5. Y. Arata, F. Matsuda, H. Nakagawa, and S. Katayama: Trans. JWRI, 1978, vol. 7, pp. 169-72.

6. F. Matsuda, H. Nakagawa, T. Uehara, S. Katayama, and Y. Arata: Trans. JWRI, 1979, vol. 8, pp. 105-12.

7. F. Matsuda, S. Katayama, and Y. Arata: Trans. JWRI, 1983, vol. 12 , pp. 247-52.

8. F. Hull: Weld. J., 1959, vol. 38, pp. 176s-81s.

9. B. Alexandrov and J. Lippold, In Hot Cracking Phenomena in Welds III, Springer, Berlin, 2011, pp. 317-31.

10. M.G. Collins and J.C. Lippold: Weld. J., 2003, vol. 82, pp. $288 \mathrm{~s}-95 \mathrm{~s}$.

11. S. Mandziej, In Hot Cracking Phenomena in Welds, Springer, 2005, pp. $347-76$

12. F. Mohammadi, F.F. Eliyan, and A. Alfantazi: Corros. Sci., 2012, vol. 63 , pp. 323-33.

13. J.C. Lippold: Joining of Advanced and Specialty Materials VII, 2005. https://www.asminternational.org/documents/10192/184977 0/5116_01_WEBa.pdf.
14. L. Aucott, D. Huang, H.B. Dong, S.W. Wen, J. Marsden, A. Rack, and A.C.F. Cocks: Metall. Mater. Trans. A, 2018, vol. 49, pp. 1674-82.

15. L. Aucott, D. Huang, H.B. Dong, S.W. Wen, J.A. Marsden, A. Rack, and A.C. Cocks: Sci. Rep., 2017, vol. 7, p. 40255.

16. E. Bayraktar, D. Kaplan, L. Devillers, and J.P. Chevalier: $J$. Mater. Process. Technol., 2007, vol. 189, pp. 114-25.

17. T.W. Nelson, J.C. Lippold, and M.J. Mills: Weld. J., 1999, vol. 78, pp. $329 \mathrm{~s}-37 \mathrm{~s}$.

18. Y.Z. Zhou, A. Volek, and N.R. Green: Acta Mater., 2008, vol. 56, pp. 2631-37.

19. A. Stangeland, A. Mo, O. Nielsen, D. Eskin, and M. M'hamdi: Metall. Mater. Trans. A, 2004, vol. 35A, pp. 2903-15.

20. G. Reinhart, A. Buffet, H. Nguyen-Thi, B. Billia, H. Jung, N. Mangelinck-Noël, N. Bergeon, T. Schenk, J. Härtwig, and J. Baruchel: Metall. Mater. Trans. A, 2008, vol. 39A, pp. 865-74.

21. C. Iso: Destructive Tests on Welds in Metallic Materials-Hot Cracking Tests for Weldments-Arc Welding Processes-Part 3: Externally Loaded Tests, vol. 3, International Organization for Standardization, 2005.

22. H. Tamura, N. Kato, S. Ochiai, and Y. Katagiri: Trans. Jpn. Weld. Soc., 1977, vol. 8, pp. 143-49.

23. T. Ogawa and E. Tsunetomi: in 10th Golden Gate Metals and Welding Conference, San Francisco, 1979

24. W. Savage and C. Lundin: Weld. J., 1965, vol. 44, pp. 433-42.

25. J. Andersson, J. Jacobsson, A. Brederholm and H. Hänninen: in Cracking Phenomena in Welds iv, 2016, pp. 25-36.

26. S. Goodman, J. Lee, and E. Nichols: Weld. J., 1968, vol. 47, pp. 371-77.

27. R.A. Owen, R.V. Preston, P.J. Withers, H.R. Shercliff, and P.J. Webster: Mater. Sci. Eng. A Struct., 2003, vol. 346, pp. 159-67.

28. J.C. Lippold and W.M. Lin: in Mater. Sci. Forum, Trans Tech Publ: 1996, pp 1685-90.

29. T. Boellinghaus, H. Herold, C.E. Cross, and J.C. Lippold: Hot Cracking Phenomena in Welds II, Springer, Berlin, 2008.

30. C.L.M.D. Silva and A. Scotti: Meas. Sci. Technol., 2004, vol. 15, pp. 2215-23.

31. D. Hayduk, B.K. Damkrocer, G.R. Edwards, and D.L. Olson: Weld. J., 1986, vol. 65, pp. 251-60.

32. V. Shankar, T.P.S. Gill, S.L. Mannan, and S. Sundaresan: Sci. Technol. Weld. Join., 2013, vol. 5, pp. 91-97.

33. American Petroleum Institute (Api), American Petroleum Institute (API), 2000.

34. G. Murry: Traitement Thermique (France), 1992, pp. 35-39.

35. G. Srinivasan, M. Divya, S.K. Albert, A.K. Bhaduri, A. Klenk, and D.R.G. Achar: Weld. World, 2010, vol. 54, pp. R322-32.

36. E.J. Chun, H. Baba, K. Nishimoto, and K. Saida: Met. Mater. Int., 2015, vol. 21, pp. 543-53.

37. D. Rosenthal: Weld. J., 1941, vol. 20, pp. 220-34.

38. J.C. Lippold, T. Boellinghaus, and C.E. Cross: Hot Cracking Phenomena in Welds III, Springer, Berlin, 2011.

39. T. Boellinghaus, J.C. Lippold, and C.E. Cross: Cracking Phenomena in Welds IV, Springer, Berlin, 2016, pp. 38-39.

40. N.E. Nissley and J.C. Lippold: Weld. J., 2003, vol. 82, pp. 355-64. 41. M. Collins and J. Lippold: Weld. J., 2003, vol. 82, pp. 288-95.

42. J.C. Lippold, J.W. Sowards, G.M. Murray, B.T. Alexandrov, and A.J. Ramirez: in 2007 2nd International Workshop on Hot Cracking Phenomena in Welds, Springer, Berlin, 2008, pp. 147-70.

43. C.E. Cross and N. Coniglio: in 2007 2nd International Workshop on Hot Cracking Phenomena in Welds, Springer, Berlin, 2008, pp $39-58$.

44. L. Aucott, S. Wen, and H. Dong: in ASME 2014 33rd International Conference on Ocean, Offshore and Arctic Engineering, San Francisco, California, USA, 2014.

45. L. Aucott, S.W. Wen, and H. Dong: Mater. Sci. Eng. A, 2015, vol. 622, pp. 194-203.

46. V. Quiroz, A. Gumenyuk, and M. Rethmeier: J. Strain Anal. Eng. Des., 2012, vol. 47, pp. 587-99.

47. T. Soysal and S. Kou: Acta Mater., 2018, vol. 143, pp. 181-97.

48. S. Kou: Welding metallurgy. Second ed., John Wiley \& Sons, Inc., New York, 2003.

Publisher's Note Springer Nature remains neutral with regard to jurisdictional claims in published maps and institutional affiliations. 